\title{
Fixed point results, generalized Ulam-Hyers stability and well-posedness via $\alpha$-admissible mappings in $b$-metric spaces
}

\author{
Supak Phiangsungnoen ${ }^{1,2}$, Wutiphol Sintunavarat $^{3 *}$ and Poom Kumam ${ }^{1,2^{*}}$
}

\author{
"Correspondence: \\ wutiphol@mathstat.sci.tu.ac.th; \\ poom_teun@hotmail.com; \\ poom.kum@kmutt.ac.th \\ 'Department of Mathematics, \\ Faculty of Science, King Mongkut's \\ University of Technology Thonburi \\ (KMUTT), 126 Pracha Uthit Rd., Bang \\ Mod, Thung Khru, Bangkok, 10140, \\ Thailand \\ ${ }^{2}$ Centre of Excellence in \\ Mathematics, CHE, Si Ayutthaya \\ Road, Bangkok, 10400, Thailand \\ Full list of author information is \\ available at the end of the article
}

\begin{abstract}
In this paper, we prove the existence and uniqueness of a fixed point for some new classes of contractive mappings via $\alpha$-admissible mappings in the framework of $b$-metric spaces. We also present an example to illustrate the usability of the obtained results. The generalized Ulam-Hyers stability and well-posedness of a fixed point equation via $\alpha$-admissible mappings in $b$-metric spaces are given.

MSC: 46S40; 47S40; 47H10
\end{abstract}

Keywords: $\alpha$-admissible mappings; $b$-metric spaces; fixed points; generalized Ulam-Hyers stability; well-posedness

\section{Introduction and preliminaries}

\subsection{The $b$-metric space}

The Banach contraction mapping principle is the most important in mathematics analysis, it guarantees the existence and uniqueness of a fixed point for certain self-mapping in metric spaces and provides a constructive method to find this fixed point. Several authors have obtained fixed point and common fixed point results for various classes of mappings in the setting of several spaces (see [1-6] and the references therein).

In 1993, Czerwik [7] introduced $b$-metric spaces as a generalization of metric spaces and proved the contraction mapping principle in $b$-metric spaces that is an extension of the famous Banach contraction principle in metric spaces. Since then, a number of authors have investigated fixed point theorems in $b$-metric spaces (see [8-11] and the references therein).

Definition 1.1 (Bakhtin [8], Czerwik [12]) Let $X$ be a nonempty set, and let the functional $d: X \times X \rightarrow[0, \infty)$ satisfy:

(b1) $d(x, y)=0$ if and only if $x=y$;

(b2) $d(x, y)=d(y, x)$ for all $x, y \in X$;

(b3) there exists a real number $s \geq 1$ such that $d(x, z) \leq s[d(x, y)+d(y, z)]$ for all $x, y, z \in X$.

Then $d$ is called a $b$-metric on $X$ and a pair $(X, d)$ is called a $b$-metric space with coefficient $s$.

(02014 Phiangsungnoen et al: licensee Springer. This is an Open Access article distributed under the terms of the Creative Commons Attribution License (http://creativecommons.org/licenses/by/2.0), which permits unrestricted use, distribution, and reproduction in any medium, provided the original work is properly cited. 
Remark 1.2 If we take $s=1$ in the above definition, then $b$-metric spaces turn into ordinary metric spaces. Hence, the class of $b$-metric spaces is larger than the class of metric spaces.

For examples of $b$-metric spaces, see [7, 8, 12-14].

Example 1.3 The set $l_{p}(\mathbb{R})$ with $0<p<1$, where $l_{p}(\mathbb{R}):=\left\{\left.\left\{x_{n}\right\} \subset \mathbb{R}\left|\sum_{n=1}^{\infty}\right| x_{n}\right|^{p}<\infty\right\}$, together with the functional $d: l_{p}(\mathbb{R}) \times l_{p}(\mathbb{R}) \rightarrow[0, \infty)$,

$$
d(x, y):=\left(\sum_{n=1}^{\infty}\left|x_{n}-y_{n}\right|^{p}\right)^{\frac{1}{p}}
$$

where $x=\left\{x_{n}\right\}, y=\left\{y_{n}\right\} \in l_{p}(\mathbb{R})$, is a $b$-metric space with coefficient $s=2^{\frac{1}{p}}>1$. Notice that the above result holds for the general case $l_{p}(X)$ with $0<p<1$, where $X$ is a Banach space.

Example 1.4 Let $X$ be a set with the cardinal $\operatorname{card}(X) \geq 3$. Suppose that $X=X_{1} \cup X_{2}$ is a partition of $X$ such that $\operatorname{card}\left(X_{1}\right) \geq 2$. Let $s>1$ be arbitrary. Then the functional $d: X \times$ $X \rightarrow[0, \infty)$ defined by

$$
d(x, y):= \begin{cases}0, & x=y, \\ 2 s, & x, y \in X_{1}, \\ 1, & \text { otherwise }\end{cases}
$$

is a $b$-metric on $X$ with coefficient $s>1$.

Definition 1.5 (Boriceanu et al. [14]) Let $(X, d)$ be a $b$-metric space. Then a sequence $\left\{x_{n}\right\}$ in $X$ is called:

(a) convergent if and only if there exists $x \in X$ such that $d\left(x_{n}, x\right) \rightarrow 0$ as $n \rightarrow \infty$;

(b) Cauchy if and only if $d\left(x_{n}, x_{m}\right) \rightarrow 0$ as $m, n \rightarrow \infty$.

Lemma 1.6 (Czerwik [12]) Let $(X, d)$ be a b-metric space, and let $\left\{x_{k}\right\}_{k=0}^{n} \subset X$. Then

$$
d\left(x_{0}, x_{n}\right) \leq s d\left(x_{0}, x_{1}\right)+\cdots+s^{n-1} d\left(x_{n-2}, x_{n-1}\right)+s^{n-1} d\left(x_{n-1}, x_{n}\right) .
$$

Definition 1.7 (Rus [15]) A mapping $\psi:[0, \infty) \rightarrow[0, \infty)$ is called a comparison function if it is increasing and $\psi^{n}(t) \rightarrow 0$ as $n \rightarrow \infty$ for any $t \in[0, \infty)$, where $\psi^{n}$ is the $n$th iterate of $\psi$.

Lemma 1.8 (Rus [15], Berinde [16]) If $\psi:[0, \infty) \rightarrow[0, \infty)$ is a comparison function, then

(1) $\psi^{n}$ is also a comparison function;

(2) $\psi$ is continuous at 0 ;

(3) $\psi(t)<t$ for any $t>0$.

The concept of $(c)$-comparison function was introduced by Berinde [16] in the following definition. 
Definition 1.9 (Berinde [16]) A function $\psi:[0, \infty) \rightarrow[0, \infty)$ is said to be a $(c)$-comparison function if

(1) $\psi$ is increasing;

(2) there exist $n_{0} \in \mathbb{N}, k \in(0,1)$ and a convergent series of nonnegative terms $\sum_{n=1}^{\infty} \epsilon_{n}$ such that $\psi^{n+1}(t) \leq k \psi^{n}(t)+\epsilon_{n}$ for $n \geq n_{0}$ and any $t \in[0, \infty)$.

Here we recall the definitions of the following class of $(b)$-comparison functions as given by Berinde [17] in order to extend some fixed point results to the class of $b$-metric spaces.

Definition 1.10 (Berinde [17]) Let $s \geq 1$ be a real number. A mapping $\psi:[0, \infty) \rightarrow[0, \infty)$ is called a $(b)$-comparison function if the following conditions are fulfilled:

(1) $\psi$ is increasing;

(2) there exist $n_{0} \in \mathbb{N}, k \in(0,1)$ and a convergent series of nonnegative terms $\sum_{n=1}^{\infty} \epsilon_{n}$ such that $s^{n+1} \psi^{n+1}(t) \leq k s^{n} \psi^{n}(t)+\epsilon_{n}$ for $n \geq n_{0}$ and any $t \in[0, \infty)$.

In this work, we use $\Psi_{b}$ to denote the class of all (b)-comparison functions $\psi:[0, \infty) \rightarrow$ $[0, \infty)$ unless and until it is stated otherwise. It is evident that the concept of $(b)$ comparison function reduces to that of $(c)$-comparison function when $s=1$.

Lemma 1.11 (Berinde [13]) If $\psi:[0, \infty) \rightarrow[0, \infty)$ is a (b)-comparison function, then the following assertions hold:

(i) the series $\sum_{n=0}^{\infty} s^{n} \psi^{n}(t)$ converges for any $t \in[0, \infty)$;

(ii) the function $S:[0, \infty) \rightarrow[0, \infty)$ defined by $S(t)=\sum_{n=0}^{\infty} s^{n} \psi^{n}(t)$ for $t \in[0, \infty)$ is increasing and continuous at 0 .

\subsection{The generalized Ulam-Hyers stability}

Stability problems of functional analysis play the most important role in mathematics analysis. They were introduced by Ulam [18], he was concerned with the stability of group homomorphisms. Afterward, Hyers [19] gave a first affirmative partial answer to the question of Ulam for a Banach space, this type of stability is called Ulam-Hyers stability. Several authors have considered Ulam-Hyers stability results in fixed point theory, and remarkable results on the stability of certain classes of functional equations via fixed point approach have been obtained (see [20-26] and the references therein).

We recall the following definitions in the class of $b$-metric spaces.

Definition 1.12 Let $(X, d)$ be a $b$-metric space with coefficient $s$, and let $f: X \rightarrow X$ be an operator. By definition, the fixed point equation

$$
u=f(u), \quad u \in X
$$

is said to be generalized Ulam-Hyers stable in the framework of a $b$-metric space if there exists an increasing operator $\varphi:[0, \infty) \rightarrow[0, \infty)$, continuous at 0 and $\varphi(0)=0$, such that for each $\varepsilon>0$ and an $\varepsilon$-solution $v^{*} \in X$, that is,

$$
d\left(v^{*}, f\left(v^{*}\right)\right) \leq \varepsilon,
$$


there exists a solution $u^{*} \in X$ of the fixed point equation (1.1) such that

$$
d\left(v^{*}, u^{*}\right) \leq \varphi(s \varepsilon)
$$

If $\varphi(t):=c t$ for all $t \in[0, \infty)$, where $c>0$, then (1.1) is said to be Ulam-Hyers stable in the framework of a $b$-metric space.

Remark 1.13 If $s=1$, then Definition 1.12 reduces to the generalized Ulam-Hyers stability in metric spaces. Also, if $\varphi(t):=c t$ for all $t \in[0, \infty)$, where $c>0$, then it reduces to the classical Ulam-Hyers stability.

\section{$1.3 \alpha$-Admissible mappings}

In 2012, Samet et al. [27] introduced the concept of $\alpha$-admissible mappings and established fixed point theorems for such mappings in complete metric spaces. Moreover, they showed some examples and applications to ordinary differential equations. There are many researchers who improved and generalized fixed point results by using the concept of $\alpha$-admissible mapping for single-valued and multivalued mappings (see [28-33]).

Definition 1.14 (Samet et al. [27]) Let $X$ be a nonempty set, $f: X \rightarrow X$ and $\alpha: X \times X \rightarrow$ $[0, \infty)$. We say that $f$ is an $\alpha$-admissible mapping if it satisfies the following condition:

$$
\text { for } x, y \in X, \quad \alpha(x, y) \geq 1 \quad \Longrightarrow \quad \alpha(f(x), f(y)) \geq 1 \text {. }
$$

Example 1.15 (Samet et al. [27]) Let $X=(0, \infty)$. Define $f: X \rightarrow X$ and $\alpha: X \times X \rightarrow[0, \infty)$ by

$$
f(x)=\ln (x) \quad \text { for all } x \in X
$$

and

$$
\alpha(x, y)= \begin{cases}2, & \text { if } x \geq y \\ 0, & \text { if } x<y\end{cases}
$$

Then $f$ is $\alpha$-admissible.

Example 1.16 Let $X=\mathbb{R}$. Define $f: X \rightarrow X$ and $\alpha: X \times X \rightarrow[0, \infty)$ by

$$
f(x)= \begin{cases}\ln \left(x^{2}+1\right), & \text { if } x>1 \\ \frac{x}{3}, & \text { if } 0 \leq x \leq 1 \\ x, & \text { otherwise }\end{cases}
$$

and

$$
\alpha(x, y)= \begin{cases}1, & \text { if } x, y \in[0,1] \\ \ln 1.5, & \text { otherwise. }\end{cases}
$$

Then $f$ is $\alpha$-admissible. 
Recently Bota et al. [34] proved the existence and uniqueness of fixed point theorems. They also studied the generalized Ulam-Hyers stability results via an $\alpha$-admissible mapping in a $b$-metric space. The purpose of this paper is to establish the existence and uniqueness of fixed point theorems for some new types of contractive mappings via $\alpha$-admissible mappings. We also give some examples to show that our fixed point theorems for new types of contractive mappings are independent. The generalized Ulam-Hyers stability and well-posedness of a fixed point equation for these classes in the framework of $b$-metric spaces are proved.

\section{Fixed point results in $b$-metric spaces}

In this section, we prove the existence and uniqueness of fixed point theorems in a $b$ metric space.

Theorem 2.1 Let $(X, d)$ be a complete b-metric space with coefficient s, let $f: X \rightarrow X$ and $\alpha: X \times X \rightarrow[0, \infty)$ be two mappings and $\psi \in \Psi_{b}$. Suppose that the following conditions hold:

(a) $f$ is $\alpha$-admissible;

(b) there exists $x_{0} \in X$ such that $\alpha\left(x_{0}, f\left(x_{0}\right)\right) \geq 1$;

(c) for all $x, y \in X$, we have

$$
\alpha(x, f(x)) \alpha(y, f(y)) d(f(x), f(y)) \leq \psi(d(x, y))
$$

(d) if $\left\{x_{n}\right\}$ is a sequence in $X$ such that $x_{n} \rightarrow x$ as $n \rightarrow \infty$ and $\alpha\left(x_{n}, f\left(x_{n}\right)\right) \geq 1$ for all $n \in \mathbb{N}$, then $\alpha(x, f(x)) \geq 1$.

Then $f$ has a unique fixed point $x^{*}$ in $X$ such that $\alpha\left(x^{*}, f\left(x^{*}\right)\right) \geq 1$.

Proof Let $x_{0} \in X$ such that $\alpha\left(x_{0}, f\left(x_{0}\right)\right) \geq 1$ (from condition (b)). We define the sequence $\left\{x_{n}\right\}$ in $X$ such that

$$
x_{n}=f\left(x_{n-1}\right) \quad \text { for all } n \in \mathbb{N} \text {. }
$$

Since $f$ is $\alpha$-admissible and

$$
\alpha\left(x_{0}, x_{1}\right)=\alpha\left(x_{0}, f\left(x_{0}\right)\right) \geq 1
$$

we deduce that

$$
\alpha\left(x_{1}, f\left(x_{1}\right)\right)=\alpha\left(f\left(x_{0}\right), f\left(x_{1}\right)\right) \geq 1 .
$$

By induction, we get

$$
\alpha\left(x_{n-1}, f\left(x_{n-1}\right)\right) \geq 1 \quad \text { for all } n \in \mathbb{N} .
$$

Next, we will show that $\left\{x_{n}\right\}$ is a Cauchy sequence in $X$. For each $n \in \mathbb{N}$, we have

$$
\begin{aligned}
d\left(x_{n}, x_{n+1}\right) & =d\left(f\left(x_{n-1}\right), f\left(x_{n}\right)\right) \\
& \leq \alpha\left(x_{n-1}, f\left(x_{n-1}\right)\right) \alpha\left(x_{n}, f\left(x_{n}\right)\right) d\left(f\left(x_{n-1}\right), f\left(x_{n}\right)\right) \\
& \leq \psi\left(d\left(x_{n-1}, x_{n}\right)\right) .
\end{aligned}
$$


By repeating the process above, we get

$$
d\left(x_{n}, x_{n+1}\right) \leq \psi^{n}\left(d\left(x_{0}, x_{1}\right)\right) \quad \text { for all } n \in \mathbb{N}
$$

For $m, n \in \mathbb{N}$ with $m>n$, we have

$$
\begin{aligned}
d\left(x_{n}, x_{m}\right) \leq & s d\left(x_{n}, x_{n+1}\right)+s^{2} d\left(x_{n+1}, x_{n+2}\right)+\cdots+s^{m-n-2} d\left(x_{m-3}, x_{m-2}\right) \\
& +s^{m-n-1} d\left(x_{m-2}, x_{m-1}\right)+s^{m-n} d\left(x_{m-1}, x_{m}\right) \\
\leq & s \psi^{n}\left(d\left(x_{0}, x_{1}\right)\right)+s^{2} \psi^{n+1}\left(d\left(x_{0}, x_{1}\right)\right)+\cdots+s^{m-n-2} \psi^{m-3}\left(d\left(x_{0}, x_{1}\right)\right) \\
& +s^{m-n-1} \psi^{m-2}\left(d\left(x_{0}, x_{1}\right)\right)+s^{m-n} \psi^{m-1}\left(d\left(x_{0}, x_{1}\right)\right) \\
= & \frac{1}{s^{n-1}}\left[s^{n} \psi^{n}\left(d\left(x_{0}, x_{1}\right)\right)+s^{n+1} \psi^{n+1}\left(d\left(x_{0}, x_{1}\right)\right)+\cdots+s^{m-2} \psi^{m-2}\left(d\left(x_{0}, x_{1}\right)\right)\right. \\
& \left.+s^{m-1} \psi^{m-1}\left(d\left(x_{0}, x_{1}\right)\right)\right] .
\end{aligned}
$$

Define $S_{n}:=\sum_{i=0}^{n} s^{i} \psi^{i}\left(d\left(x_{0}, x_{1}\right)\right)$ for all $n \in \mathbb{N}$. This implies that

$$
d\left(x_{n}, x_{m}\right) \leq \frac{1}{s^{n-1}}\left[S_{m-1}-S_{n-1}\right] \quad \text { for all } n, m \in \mathbb{N} \text { with } m>n
$$

By Lemma 1.11 we know that the series $\sum_{i=0}^{\infty} s^{i} \psi^{i}\left(d\left(x_{0}, x_{1}\right)\right)$ converges. Therefore, $\left\{x_{n}\right\}$ is a Cauchy sequence in $X$. By the completeness of $X$, there exists $x^{*} \in X$ such that $x_{n} \rightarrow x^{*}$ as $n \rightarrow \infty$. Using condition (d), we get $\alpha\left(x^{*}, f\left(x^{*}\right)\right) \geq 1$. From (2.1), we have

$$
\begin{aligned}
d\left(f\left(x^{*}\right), x^{*}\right) & \leq s\left[d\left(f\left(x^{*}\right), x_{n}\right)+d\left(x_{n}, x^{*}\right)\right] \\
& =s\left[d\left(f\left(x^{*}\right), f\left(x_{n-1}\right)\right)+d\left(x_{n}, x^{*}\right)\right] \\
& \leq s\left[\alpha\left(x^{*}, f\left(x^{*}\right)\right) \alpha\left(x_{n-1}, f\left(x_{n-1}\right)\right) d\left(f\left(x^{*}\right), f\left(x_{n-1}\right)\right)+d\left(x_{n}, x^{*}\right)\right] \\
& \leq s\left[\psi\left(d\left(x^{*}, x_{n-1}\right)\right)+d\left(x_{n}, x^{*}\right)\right]
\end{aligned}
$$

for all $n \in \mathbb{N}$. Letting $n \rightarrow \infty$, since $\psi$ is continuous at 0 , we obtain

$$
d\left(f\left(x^{*}\right), x^{*}\right)=0
$$

It implies that $f\left(x^{*}\right)=x^{*}$, that is, $x^{*}$ is a fixed point of $f$ such that $\alpha\left(x^{*}, f\left(x^{*}\right)\right) \geq 1$.

Next, we prove the uniqueness of the fixed point of $f$. Let $y^{*}$ be another fixed point of $f$ such that

$$
\alpha\left(y^{*}, f\left(y^{*}\right)\right) \geq 1
$$

It follows that

$$
\begin{aligned}
d\left(x^{*}, y^{*}\right) & =d\left(f\left(x^{*}\right), f\left(y^{*}\right)\right) \\
& \leq \alpha\left(x^{*}, f\left(x^{*}\right)\right) \alpha\left(y^{*}, f\left(y^{*}\right)\right) d\left(f\left(x^{*}\right), f\left(y^{*}\right)\right) \\
& \leq \psi\left(d\left(x^{*}, y^{*}\right)\right) \\
& <d\left(x^{*}, y^{*}\right),
\end{aligned}
$$


which is a contradiction. Therefore, $x^{*}$ is the unique fixed point of $f$ such that $\alpha\left(x^{*}\right.$, $\left.f\left(x^{*}\right)\right) \geq 1$. This completes the proof.

Theorem 2.2 Let $(X, d)$ be a complete b-metric space with coefficient s, let $f: X \rightarrow X$ and $\alpha: X \times X \rightarrow[0, \infty)$ be two mappings and $\psi \in \Psi_{b}$. Suppose that the following conditions hold:

(a) $f$ is $\alpha$-admissible;

(b) there exists $x_{0} \in X$ such that $\alpha\left(x_{0}, f\left(x_{0}\right)\right) \geq 1$;

(c) there exists $\xi \geq 1$ such that

$$
[d(f(x), f(y))+\xi]^{\alpha(x, f(x)) \alpha(y, f(y))} \leq \psi(d(x, y))+\frac{\xi}{S}
$$

for all $x, y \in X$

(d) if $\left\{x_{n}\right\}$ is a sequence in $X$ such that $x_{n} \rightarrow x$ as $n \rightarrow \infty$ and $\alpha\left(x_{n}, f\left(x_{n}\right)\right) \geq 1$ for all $n \in \mathbb{N}$, then $\alpha(x, f(x)) \geq 1$.

Then $f$ has a unique fixed point $x^{*}$ in $X$ such that $\alpha\left(x^{*}, f\left(x^{*}\right)\right) \geq 1$.

Proof Let $x_{0} \in X$ such that $\alpha\left(x_{0}, f\left(x_{0}\right)\right) \geq 1$ (from condition (b)). We define the sequence $\left\{x_{n}\right\}$ in $X$ such that

$$
x_{n}=f\left(x_{n-1}\right) \quad \text { for all } n \in \mathbb{N} \text {. }
$$

Since $f$ is $\alpha$-admissible and $\alpha\left(x_{0}, x_{1}\right)=\alpha\left(x_{0}, f\left(x_{0}\right)\right) \geq 1$, we get

$$
\alpha\left(f\left(x_{0}\right), f\left(x_{1}\right)\right)=\alpha\left(x_{1}, f\left(x_{1}\right)\right) \geq 1 .
$$

By induction, we get

$$
\alpha\left(x_{n-1}, f\left(x_{n-1}\right)\right) \geq 1 \quad \text { for all } n \in \mathbb{N} .
$$

Next, we will show that $\left\{x_{n}\right\}$ is a Cauchy sequence in $X$. For each $n \in \mathbb{N}$, we have

$$
\begin{aligned}
d\left(x_{n}, x_{n+1}\right)+\xi & =d\left(f\left(x_{n-1}\right), f\left(x_{n}\right)\right)+\xi \\
& \leq\left[d\left(f\left(x_{n-1}\right), f\left(x_{n}\right)\right)+\xi\right]^{\alpha\left(x_{n-1}, f\left(x_{n-1}\right)\right) \alpha\left(x_{n} f\left(x_{n}\right)\right)} \\
& \leq \psi\left(d\left(x_{n-1}, x_{n}\right)\right)+\frac{\xi}{s} \\
& \leq \psi\left(d\left(x_{n-1}, x_{n}\right)\right)+\xi .
\end{aligned}
$$

Now, we get

$$
d\left(x_{n}, x_{n+1}\right) \leq \psi\left(d\left(x_{n-1}, x_{n}\right)\right) \leq \psi^{n}\left(d\left(x_{0}, x_{1}\right)\right) \quad \text { for all } n \in \mathbb{N} .
$$

Following the proof of Theorem 2.1, we know that $\left\{x_{n}\right\}$ is a Cauchy sequence in $X$. Since $(X, d)$ is complete, there exists $x^{*} \in X$ such that $x_{n} \rightarrow x^{*}$ as $n \rightarrow \infty$. By condition (d), we 
have $\alpha\left(x^{*}, f\left(x^{*}\right)\right) \geq 1$ for all $n \in \mathbb{N}$. From (2.2), we get

$$
\begin{aligned}
d\left(f\left(x^{*}\right), x^{*}\right)+\xi & \leq s\left[d\left(f\left(x^{*}\right), x_{n}\right)+d\left(x_{n}, x^{*}\right)\right]+\xi \\
& \leq s\left[d\left(f\left(x^{*}\right), f\left(x_{n-1}\right)\right)+\xi+d\left(x_{n}, x^{*}\right)\right] \\
& \leq s\left[\left(d\left(f\left(x^{*}\right), f\left(x_{n-1}\right)\right)+\xi\right)^{\alpha\left(x^{*}, f\left(x^{*}\right)\right) \alpha\left(x_{n-1} f\left(x_{n-1}\right)\right)}+d\left(x_{n}, x^{*}\right)\right] \\
& \leq s\left[\psi\left(d\left(x^{*}, x_{n-1}\right)\right)+\frac{\xi}{s}+d\left(x_{n}, x^{*}\right)\right]
\end{aligned}
$$

for all $n \in \mathbb{N}$. Letting $n \rightarrow \infty$ and $\psi$ be continuous at 0 , we obtain that

$$
d\left(f\left(x^{*}\right), x^{*}\right)=0 .
$$

This implies that $f\left(x^{*}\right)=x^{*}$, that is, $x^{*}$ is a fixed point of $f$ such that $\alpha\left(x^{*}, f\left(x^{*}\right)\right) \geq 1$.

Next, we prove the uniqueness of the fixed point of $f$. Let $y^{*}$ be another fixed point of $f$ such that

$$
\alpha\left(y^{*}, f\left(y^{*}\right)\right) \geq 1
$$

It follows that

$$
\begin{aligned}
d\left(x^{*}, y^{*}\right)+\xi & =d\left(f\left(x^{*}\right), f\left(y^{*}\right)\right)+\xi \\
& \leq\left[d\left(f\left(x^{*}\right), f\left(y^{*}\right)\right)+\xi\right]^{\alpha\left(x^{*}, f\left(x^{*}\right)\right) \alpha\left(y^{*}, f\left(y^{*}\right)\right)} \\
& \leq \psi\left(d\left(x^{*}, y^{*}\right)\right)+\frac{\xi}{s} \\
& \leq \psi\left(d\left(x^{*}, y^{*}\right)\right)+\xi .
\end{aligned}
$$

This shows that

$$
d\left(x^{*}, y^{*}\right) \leq \psi\left(d\left(x^{*}, y^{*}\right)\right)<d\left(x^{*}, y^{*}\right)
$$

which is a contradiction. Therefore, $x^{*}$ is the unique fixed point of $f$ such that $\alpha\left(x^{*}\right.$, $\left.f\left(x^{*}\right)\right) \geq 1$. This completes the proof.

Theorem 2.3 Let $(X, d)$ be a complete b-metric space with coefficient s, let $f: X \rightarrow X$ and $\alpha: X \times X \rightarrow[0, \infty)$ be two mappings and $\psi \in \Psi_{b}$. Suppose that the following conditions hold:

(a) $f$ is $\alpha$-admissible;

(b) there exists $x_{0} \in X$ such that $\alpha\left(x_{0}, f\left(x_{0}\right)\right) \geq 1$;

(c) there exists $\xi>1$ such that

$$
(\alpha(x, f(x)) \alpha(y, f(y))-1+\xi)^{d(f(x), f(y))} \leq \xi^{\psi(d(x, y))}
$$

for all $x, y \in X$;

(d) if $\left\{x_{n}\right\}$ is a sequence in $X$ such that $x_{n} \rightarrow x$ as $n \rightarrow \infty$ and $\alpha\left(x_{n}, f\left(x_{n}\right)\right) \geq 1$ for all $n \in \mathbb{N}$, then $\alpha(x, f(x)) \geq 1$.

Then $f$ has a unique fixed point $x^{*}$ in $X$ such that $\alpha\left(x^{*}, f\left(x^{*}\right)\right) \geq 1$. 
Proof Let $x_{0} \in X$ such that $\alpha\left(x_{0}, f\left(x_{0}\right)\right) \geq 1$ (from condition (b)). We define the sequence $\left\{x_{n}\right\}$ in $X$ such that

$$
x_{n}=f\left(x_{n-1}\right) \quad \text { for all } n \in \mathbb{N} \text {. }
$$

Since $f$ is $\alpha$-admissible and $\alpha\left(x_{0}, x_{1}\right)=\alpha\left(x_{0}, f\left(x_{0}\right)\right) \geq 1$, we get

$$
\alpha\left(f\left(x_{0}\right), f\left(x_{1}\right)\right)=\alpha\left(x_{1}, f\left(x_{1}\right)\right) \geq 1 .
$$

By induction, we get

$$
\alpha\left(x_{n-1}, f\left(x_{n-1}\right)\right) \geq 1 \quad \text { for all } n \in \mathbb{N} \text {. }
$$

Next, we will show that $\left\{x_{n}\right\}$ is a Cauchy sequence in $X$. For each $n \in \mathbb{N}$, we have

$$
\begin{aligned}
\xi^{d\left(x_{n}, x_{n+1}\right)} & =\xi^{d\left(f\left(x_{n-1}\right), f\left(x_{n}\right)\right)} \\
& \leq\left(\alpha\left(x_{n-1}, f\left(x_{n-1}\right)\right) \alpha\left(x_{n}, f\left(x_{n}\right)\right)-1+\xi\right)^{d\left(f\left(x_{n-1}\right), f\left(x_{n}\right)\right)} \\
& \leq \xi^{\psi\left(d\left(x_{n-1}, x_{n}\right)\right)} .
\end{aligned}
$$

Since $\xi>1$, we get

$$
d\left(x_{n}, x_{n+1}\right) \leq \psi\left(d\left(x_{n-1}, x_{n}\right)\right) \leq \psi^{n}\left(d\left(x_{0}, x_{1}\right)\right) \quad \text { for all } n \in \mathbb{N} .
$$

Following the proof of Theorem 2.1, we know that $\left\{x_{n}\right\}$ is a Cauchy sequence in $X$. Since $(X, d)$ is complete, there exists $x^{*} \in X$ such that $x_{n} \rightarrow x^{*}$ as $n \rightarrow \infty$. By condition (d), we have $\alpha\left(x^{*}, f\left(x^{*}\right)\right) \geq 1$ for all $n \in \mathbb{N}$. From assumption (2.3), we get

$$
\begin{aligned}
\xi^{d\left(f\left(x^{*}\right), x^{*}\right)} & \leq \xi^{s\left[d\left(f\left(x^{*}\right), x_{n}\right)+d\left(x_{n}, x^{*}\right)\right]} \\
& =\xi^{s\left(d\left(f\left(x^{*}\right), f\left(x_{n-1}\right)\right)\right)} \xi^{s\left(d\left(x_{n}, x^{*}\right)\right)} \\
& =\left(\xi^{d\left(f\left(x^{*}\right), f\left(x_{n-1}\right)\right)}\right)^{s}\left(\xi^{d\left(x_{n}, x^{*}\right)}\right)^{s} \\
& \leq\left(\left(\alpha\left(x_{n-1}, f\left(x_{n-1}\right)\right) \alpha\left(x^{*}, f\left(x^{*}\right)\right)-1+\xi\right)^{d\left(f\left(x^{*}\right), f\left(x_{n-1}\right)\right)}\right)^{s}\left(\xi^{d\left(x_{n}, x^{*}\right)}\right)^{s} \\
& \leq\left(\xi^{\psi\left(d\left(x^{*}, x_{n-1}\right)\right)}\right)^{s}\left(\xi^{d\left(x_{n}, x^{*}\right)}\right)^{s} \\
& =\xi^{s\left[\left(d\left(x^{*}, x_{n-1}\right)\right)+d\left(x_{n}, x^{*}\right)\right]}
\end{aligned}
$$

for all $n \in \mathbb{N}$. Since $\xi>1$, it implies that

$$
d\left(f\left(x^{*}\right), x^{*}\right) \leq s\left[\psi\left(d\left(x^{*}, x_{n-1}\right)\right)+d\left(x_{n}, x^{*}\right)\right] .
$$

Letting $n \rightarrow \infty$, since $\psi$ is continuous at 0 , we obtain that

$$
d\left(f\left(x^{*}\right), x^{*}\right)=0
$$

It implies that $f\left(x^{*}\right)=x^{*}$, that is, $x^{*}$ is a fixed point of $f$ such that $\alpha\left(x^{*}, f\left(x^{*}\right)\right) \geq 1$. 
Next, we prove the uniqueness of the fixed point of $f$. Let $y^{*}$ be another fixed point of $f$ such that

$$
\alpha\left(y^{*}, f\left(y^{*}\right)\right) \geq 1
$$

It follows that

$$
\begin{aligned}
\xi^{d\left(x^{*}, y^{*}\right)} & =\xi^{d\left(f\left(x^{*}\right), f\left(y^{*}\right)\right)} \\
& \leq\left(\alpha\left(x^{*}, f\left(x^{*}\right)\right) \alpha\left(y^{*}, f\left(y^{*}\right)\right)-1+\xi\right)^{d\left(f\left(x^{*}\right), f\left(y^{*}\right)\right)} \\
& \leq \xi^{\psi\left(d\left(x^{*}, y^{*}\right)\right)} .
\end{aligned}
$$

Since $\xi>1$, we have

$$
d\left(x^{*}, y^{*}\right) \leq \psi\left(d\left(x^{*}, y^{*}\right)\right)<d\left(x^{*}, y^{*}\right)
$$

which is a contradiction. Therefore, $x^{*}$ is a unique fixed point of $f$ such that $\alpha\left(x^{*}, f\left(x^{*}\right)\right) \geq 1$. This completes the proof.

If we set $\alpha(x, y)=1$ for all $x, y \in X$ in Theorems 2.1 or 2.2 or 2.3 , we get the following results.

Corollary 2.4 Let $(X, d)$ be a complete $b$-metric space with coefficient $s$, let $f: X \rightarrow X$ and $\psi \in \Psi_{b}$, we have

$$
d(f(x), f(y)) \leq \psi(d(x, y))
$$

for all $x, y \in X$. Then $f$ has a unique fixed point in $X$.

If the coefficient $s=1$ in Corollary 2.4, we obtain immediately the following fixed point theorems in metric spaces.

Corollary 2.5 (Berinde [35]) Let $(X, d)$ be a complete metric space, $f: X \rightarrow X$ be a mapping, $\psi:[0, \infty) \rightarrow[0, \infty)$ be a (c)-comparison function such that

$$
d(f(x), f(y)) \leq \psi(d(x, y))
$$

for all $x, y \in X$. Then $f$ has a unique fixed point in $X$.

Remark 2.6 If $\psi(t)=k t$, where $k \in(0,1)$ in Corollary 2.5, we obtain the Banach contraction mapping principle.

Next, we give some examples to show that the contractive conditions in our results are independent. Also, our results are real generalizations of the Banach contraction principle and several results in literature. 
Example 2.7 Let $X=[0, \infty)$ and define $d: X \times X \rightarrow[0, \infty)$ as

$$
d(x, y)=|x-y|^{2} \quad \text { for all } x, y \in X .
$$

Then $(X, d)$ is a complete $b$-metric space with coefficient $s=2>1$, but it is not a usual metric space.

Let us define $f: X \rightarrow X$ by

$$
f(x)= \begin{cases}\frac{x}{2(x+1)}, & x \in[0,1], \\ 10 x, & x \in(1, \infty)\end{cases}
$$

Also, define $\alpha: X \times X \rightarrow[0, \infty)$ and $\psi:[0, \infty) \rightarrow[0, \infty)$ by

$$
\alpha(x, y)= \begin{cases}1, & x, y \in[0,1], \\ 0, & \text { otherwise }\end{cases}
$$

and $\psi(t)=\frac{1}{2} t$ for all $t \geq 0$. Clearly, $f$ is an $\alpha$-admissible mapping. For all $x, y \in X$, we have

$$
\alpha(x, f(x)) \alpha(y, f(y)) d(f(x), f(y)) \leq \psi(d(x, y)) .
$$

Moreover, all the conditions of Theorem 2.1 hold. In this example, 0 is a unique fixed point of $f$.

Next, we show that the contractive condition in Theorem 2.2 cannot be applied to this example. For $x=0$ and $y=1$, we obtain that

$$
[d(f(x), f(y))+\xi]^{\alpha(x, f(x)) \alpha(y, f(y))}>\psi(d(x, y))+\frac{\xi}{s}
$$

where $\xi=1$ and $s=2$. This claims that Theorem 2.2 cannot be applied to $f$. Also, by a similar method, we can show that Theorem 2.3 cannot be applied to $f$.

Moreover, results from usual metric spaces and the Banach contraction principle are not applicable while Theorem 2.1 is applicable.

\section{The generalized Ulam-Hyers stability in $b$-metric spaces}

In this section, we prove the generalized Ulam-Hyers stability in $b$-metric spaces which corresponds to Theorems 2.1, 2.2 and 2.3.

Theorem 3.1 Let $(X, d)$ be a complete b-metric space with coefficient s. Suppose that all the hypotheses of Theorem 2.1 hold and also that the function $\varphi:[0, \infty) \rightarrow[0, \infty)$ defined by $\varphi(t):=t-s \psi(t)$ is strictly increasing and onto. If $\alpha\left(u^{*}, f\left(u^{*}\right)\right) \geq 1$ for all $u^{*} \in X$, which is an $\varepsilon$-solution, then the fixed point equation (1.1) is generalized Ulam-Hyers stable.

Proof By Theorem 2.1, we have $f\left(x^{*}\right)=x^{*}$, that is, $x^{*} \in X$ is a solution of the fixed point equation (1.1). Let $\varepsilon>0$ and $y^{*} \in X$ be an $\varepsilon$-solution, that is,

$$
d\left(y^{*}, f\left(y^{*}\right)\right) \leq \varepsilon
$$


Since $x^{*}, y^{*} \in X$ are an $\varepsilon$-solution, we have

$$
\alpha\left(x^{*}, f\left(x^{*}\right)\right) \geq 1 \quad \text { and } \quad \alpha\left(y^{*}, f\left(y^{*}\right)\right) \geq 1 .
$$

Now, we obtain

$$
\begin{aligned}
d\left(x^{*}, y^{*}\right) & =d\left(f\left(x^{*}\right), y^{*}\right) \\
& \leq s\left[d\left(f\left(x^{*}\right), f\left(y^{*}\right)\right)+d\left(f\left(y^{*}\right), y^{*}\right)\right] \\
& \leq s\left[\alpha\left(x^{*}, f\left(x^{*}\right)\right) \alpha\left(y^{*}, f\left(y^{*}\right)\right) d\left(f\left(x^{*}\right), f\left(y^{*}\right)\right)+d\left(f\left(y^{*}\right), y^{*}\right)\right] \\
& \leq s\left[\psi\left(d\left(x^{*}, y^{*}\right)\right)+d\left(f\left(y^{*}\right), y^{*}\right)\right] \\
& \leq s\left[\psi\left(d\left(x^{*}, y^{*}\right)\right)+\varepsilon\right] .
\end{aligned}
$$

It follows that

$$
d\left(x^{*}, y^{*}\right)-s\left(\psi\left(d\left(x^{*}, y^{*}\right)\right)\right) \leq s \varepsilon .
$$

Since $\varphi(t):=t-s \psi(t)$, we have

$$
\varphi\left(d\left(x^{*}, y^{*}\right)\right)=d\left(x^{*}, y^{*}\right)-s \psi\left(d\left(x^{*}, y^{*}\right)\right)
$$

This implies that

$$
d\left(x^{*}, y^{*}\right) \leq \varphi^{-1}(s \varepsilon)
$$

Notice that $\varphi^{-1}:[0, \infty) \rightarrow[0, \infty)$ exists, is increasing, continuous at 0 and $\varphi^{-1}(0)=0$. Therefore, the fixed point equation (1.1) is generalized Ulam-Hyers stable.

Theorem 3.2 Let $(X, d)$ be a complete b-metric space with coefficient s. Suppose that all the hypotheses of Theorem 2.2 hold and also that the function $\varphi:[0, \infty) \rightarrow[0, \infty)$ defined by $\varphi(t):=t-s \psi(t)$ is strictly increasing and onto. If $\alpha\left(u^{*}, f\left(u^{*}\right)\right) \geq 1$ for all $u^{*} \in X$, which is an $\varepsilon$-solution, then the fixed point equation (1.1) is generalized Ulam-Hyers stable.

Proof By Theorem 2.2, we have $f\left(x^{*}\right)=x^{*}$, that is, $x^{*} \in X$ is a solution of the fixed point equation (1.1). Let $\varepsilon>0$ and $y^{*} \in X$ be an $\varepsilon$-solution, that is,

$$
d\left(y^{*}, f\left(y^{*}\right)\right) \leq \varepsilon
$$

Since $x^{*}, y^{*} \in X$ are an $\varepsilon$-solution, we have

$$
\alpha\left(x^{*}, f\left(x^{*}\right)\right) \geq 1 \quad \text { and } \quad \alpha\left(y^{*}, f\left(y^{*}\right)\right) \geq 1 \text {. }
$$

Now, we obtain

$$
\begin{aligned}
d\left(x^{*}, y^{*}\right)+\xi & =d\left(f\left(x^{*}\right), y^{*}\right)+\xi \\
& \leq s\left[d\left(f\left(x^{*}\right), f\left(y^{*}\right)\right)+d\left(f\left(y^{*}\right), y^{*}\right)\right]+\xi
\end{aligned}
$$




$$
\begin{aligned}
& \leq s\left[d\left(f\left(x^{*}\right), f\left(y^{*}\right)\right)+d\left(f\left(y^{*}\right), y^{*}\right)+\xi\right] \\
& \leq s\left[\left(d\left(f\left(x^{*}\right), f\left(y^{*}\right)\right)+\xi\right)^{\alpha\left(x^{*}, f\left(x^{*}\right)\right) \alpha\left(y^{*}, f\left(y^{*}\right)\right)}+d\left(f\left(y^{*}\right), y^{*}\right)\right] \\
& \leq s\left[\psi\left(d\left(x^{*}, y^{*}\right)\right)+\frac{\xi}{s}+d\left(f\left(y^{*}\right), y^{*}\right)\right] \\
& \leq s\left[\psi\left(d\left(x^{*}, y^{*}\right)\right)+\varepsilon\right]+\xi .
\end{aligned}
$$

It follows that

$$
d\left(x^{*}, y^{*}\right) \leq s\left[\psi\left(d\left(x^{*}, y^{*}\right)\right)+\varepsilon\right],
$$

and then

$$
d\left(x^{*}, y^{*}\right)-s\left(\psi\left(d\left(x^{*}, y^{*}\right)\right)\right) \leq s \varepsilon .
$$

Since $\varphi(t):=t-s \psi(t)$, we have

$$
\varphi\left(d\left(x^{*}, y^{*}\right)\right)=d\left(x^{*}, y^{*}\right)-s \psi\left(d\left(x^{*}, y^{*}\right)\right) .
$$

It implies that

$$
d\left(x^{*}, y^{*}\right) \leq \varphi^{-1}(s \varepsilon)
$$

Notice that $\varphi^{-1}:[0, \infty) \rightarrow[0, \infty)$ exists, is increasing, continuous at 0 and $\varphi^{-1}(0)=0$. Therefore, the fixed point equation (1.1) is generalized Ulam-Hyers stable.

Theorem 3.3 Let $(X, d)$ be a complete b-metric space with coefficient s. Suppose that all the hypotheses of Theorem 2.3 hold and also that the function $\varphi:[0, \infty) \rightarrow[0, \infty)$ defined by $\varphi(t):=t-s \psi(t)$ is strictly increasing and onto. If $\alpha\left(u^{*}, f\left(u^{*}\right)\right) \geq 1$ for all $u^{*} \in X$, which is an $\varepsilon$-solution, then the fixed point equation (1.1) is generalized Ulam-Hyers stable.

Proof By Theorem 2.3, we have $f\left(x^{*}\right)=x^{*}$, that is, $x^{*} \in X$ is a solution of the fixed point equation (1.1). Let $\varepsilon>0$ and $y^{*} \in X$ be an $\varepsilon$-solution, that is,

$$
d\left(y^{*}, f\left(y^{*}\right)\right) \leq \varepsilon
$$

Since $x^{*}, y^{*} \in X$ are an $\varepsilon$-solution, we have

$$
\alpha\left(x^{*}, f\left(x^{*}\right)\right) \geq 1 \quad \text { and } \quad \alpha\left(y^{*}, f\left(y^{*}\right)\right) \geq 1 .
$$

Now, we obtain

$$
\begin{aligned}
\xi^{d\left(x^{*}, y^{*}\right)} & =\xi^{d\left(f\left(x^{*}\right), y^{*}\right)} \\
& \leq \xi^{s\left[d\left(f\left(x^{*}\right), f\left(y^{*}\right)\right)+d\left(f\left(y^{*}\right), y^{*}\right)\right]} \\
& =\left(\xi^{d\left(f\left(x^{*}\right), f\left(y^{*}\right)\right)}\right)^{s}\left(\xi^{d\left(f\left(y^{*}\right), y^{*}\right)}\right)^{s}
\end{aligned}
$$




$$
\begin{aligned}
& \leq\left(\left(\alpha\left(x^{*}, f\left(x^{*}\right)\right) \alpha\left(y^{*}, f\left(y^{*}\right)\right)-1+\xi\right)^{d\left(f\left(x^{*}\right), f\left(y^{*}\right)\right)}\right)^{s}\left(\xi^{d\left(f\left(y^{*}\right), y^{*}\right)}\right)^{s} \\
& \leq\left(\xi^{\psi\left(d\left(x^{*}, y^{*}\right)\right)}\right)^{s}\left(\xi^{d\left(f\left(y^{*}\right), y^{*}\right)}\right)^{s} \\
& =\xi^{s\left[\left(\left(d\left(x^{*}, y^{*}\right)\right)+d\left(f\left(y^{*}\right), y^{*}\right)\right]\right.} .
\end{aligned}
$$

Since $\xi>1$, we have

$$
\begin{aligned}
d\left(x^{*}, y^{*}\right) & \leq s\left[\psi\left(d\left(x^{*}, y^{*}\right)\right)+d\left(f\left(y^{*}\right), y^{*}\right)\right] \\
& \leq s\left[\psi\left(d\left(x^{*}, y^{*}\right)\right)+\varepsilon\right] .
\end{aligned}
$$

It follows that

$$
d\left(x^{*}, y^{*}\right)-s\left(\psi\left(d\left(x^{*}, y^{*}\right)\right)\right) \leq s \varepsilon
$$

Suppose that $\varphi(t):=t-s \psi(t)$, we have

$$
\varphi\left(d\left(x^{*}, y^{*}\right)\right)=d\left(x^{*}, y^{*}\right)-s \psi\left(d\left(x^{*}, y^{*}\right)\right) .
$$

It implies that

$$
d\left(x^{*}, y^{*}\right) \leq \varphi^{-1}(s \varepsilon)
$$

Notice that $\varphi^{-1}:[0, \infty) \rightarrow[0, \infty)$ exists, is increasing, continuous at 0 and $\varphi^{-1}(0)=0$. Therefore, the fixed point equation (1.1) is generalized Ulam-Hyers stable.

\section{Well-posedness of a function with respect to $\alpha$-admissibility in $b$-metric spaces}

In this section, we present and prove well-posedness of a function with respect to an $\alpha$ admissible mapping in $b$-metric spaces.

Definition 4.1 Let $(X, d)$ be a $b$-metric space with coefficient $s$, and let $f: X \rightarrow X, \alpha$ : $X \times X \rightarrow[0, \infty)$ be two mappings. The fixed point problem of $f$ is said to be well posed with respect to $\alpha$ if:

(i) $f$ has a unique fixed point $x^{*}$ in $X$ such that $\alpha\left(x^{*}, f\left(x^{*}\right)\right) \geq 1$;

(ii) for a sequence $\left\{x_{n}\right\}$ in $X$ such that $d\left(x_{n}, f\left(x_{n}\right)\right) \rightarrow 0$ as $n \rightarrow \infty$, then $x_{n} \rightarrow x^{*}$ as $n \rightarrow \infty$.

In the following theorems, we add a new condition to assure the well-posedness via $\alpha$ admissibility.

(S) If $\left\{x_{n}\right\}$ is a sequence in $X$ such that $d\left(x_{n}, f\left(x_{n}\right)\right) \rightarrow 0$ as $n \rightarrow \infty$, then $\alpha\left(x_{n}, f\left(x_{n}\right)\right) \geq 1$ for all $n \in \mathbb{N}$.

Theorem 4.2 Let $(X, d)$ be a complete $b$-metric space with coefficient s, let $f: X \rightarrow X$ and $\alpha: X \times X \rightarrow[0, \infty)$ be two mappings and $\psi \in \Psi_{b}$. Suppose that all the hypotheses of Theorem 2.1 and condition (S) hold. Then the fixed point equation (1.1) is well posed with respect to $\alpha$. 
Proof By Theorem 2.1, there is a unique point $x^{*} \in X$ such that $f\left(x^{*}\right)=x^{*}$ and $\alpha\left(x^{*}\right.$, $\left.f\left(x^{*}\right)\right) \geq 1$. Let $\left\{x_{n}\right\}$ be a sequence in $X$ such that $d\left(x_{n}, f\left(x_{n}\right)\right) \rightarrow 0$ as $n \rightarrow \infty$. By condition $(\mathrm{S})$, we get

$$
\alpha\left(x_{n}, f\left(x_{n}\right)\right) \geq 1
$$

Now, we have

$$
\begin{aligned}
d\left(x_{n}, x^{*}\right) & =d\left(x_{n}, f\left(x^{*}\right)\right) \\
& \leq s\left[d\left(x_{n}, f\left(x_{n}\right)\right)+d\left(f\left(x_{n}\right), f\left(x^{*}\right)\right)\right] \\
& \leq s\left[\alpha\left(x_{n}, f\left(x_{n}\right)\right) \alpha\left(x^{*}, f\left(x^{*}\right)\right) d\left(f\left(x_{n}\right), f\left(x^{*}\right)\right)+d\left(x_{n}, f\left(x_{n}\right)\right)\right] \\
& \leq s\left[\psi\left(d\left(x_{n}, x^{*}\right)\right)+d\left(x_{n}, f\left(x_{n}\right)\right)\right] .
\end{aligned}
$$

Since $\psi$ is continuous at 0 and $d\left(x_{n}, f\left(x_{n}\right)\right) \rightarrow 0$ as $n \rightarrow \infty$, it implies that $x_{n} \rightarrow x^{*}$ as $n \rightarrow \infty$. Therefore, the fixed point equation (1.1) is well posed with respect to $\alpha$.

Theorem 4.3 Let $(X, d)$ be a complete b-metric space with coefficient s, let $f: X \rightarrow X$ and $\alpha: X \times X \rightarrow[0, \infty)$ be two mappings and $\psi \in \Psi_{b}$. Suppose that all the hypotheses of Theorem 2.2 and condition (S) hold. Then the fixed point equation (1.1) is well posed with respect to $\alpha$.

Proof By Theorem 2.2, there is a unique point $x^{*} \in X$ such that $f\left(x^{*}\right)=x^{*}$ and $\alpha\left(x^{*}\right.$, $\left.f\left(x^{*}\right)\right) \geq 1$. Let $\left\{x_{n}\right\}$ be a sequence in $X$ such that $d\left(x_{n}, f\left(x_{n}\right)\right) \rightarrow 0$ as $n \rightarrow \infty$. By condition (S), we get

$$
\alpha\left(x_{n}, f\left(x_{n}\right)\right) \geq 1
$$

Now, we have

$$
\begin{aligned}
d\left(x_{n}, x^{*}\right)+\xi & =d\left(x_{n}, f\left(x^{*}\right)\right)+\xi \\
& \leq s\left[d\left(x_{n}, f\left(x_{n}\right)\right)+d\left(f\left(x_{n}\right), f\left(x^{*}\right)\right)+\xi\right] \\
& \leq s\left[\left(d\left(f\left(x_{n}\right), f\left(x^{*}\right)\right)+\xi\right)^{\alpha\left(x_{n} f\left(x_{n}\right)\right) \alpha\left(x^{*}, f\left(x^{*}\right)\right)}+d\left(x_{n}, f\left(x_{n}\right)\right)\right] \\
& \leq s\left[\psi\left(d\left(x_{n}, x^{*}\right)\right)+\frac{\xi}{s}+d\left(x_{n}, f\left(x_{n}\right)\right)\right] \\
& \leq s\left[\psi\left(d\left(x_{n}, x^{*}\right)\right)+d\left(x_{n}, f\left(x_{n}\right)\right)\right]+\xi .
\end{aligned}
$$

Since $\psi$ is continuous at 0 and $d\left(x_{n}, f\left(x_{n}\right)\right) \rightarrow 0$ as $n \rightarrow \infty$, it implies that $x_{n} \rightarrow x^{*}$ as $n \rightarrow \infty$. Therefore, the fixed point equation (1.1) is well posed with respect to $\alpha$.

Theorem 4.4 Let $(X, d)$ be a complete $b$-metric space with coefficient s, let $f: X \rightarrow X$ and $\alpha: X \times X \rightarrow[0, \infty)$ be two mappings and $\psi \in \Psi_{b}$. Suppose that all the hypotheses of Theorem 2.3 and condition (S) hold. Then the fixed point equation (1.1) is well posed with respect to $\alpha$. 
Proof By Theorem 2.3, there is a unique point $x^{*} \in X$ such that $f\left(x^{*}\right)=x^{*}$ and $\alpha\left(x^{*}\right.$, $\left.f\left(x^{*}\right)\right) \geq 1$. Let $\left\{x_{n}\right\}$ be a sequence in $X$ such that $d\left(x_{n}, f\left(x_{n}\right)\right) \rightarrow 0$ as $n \rightarrow \infty$. By condition $(\mathrm{S})$, we get

$$
\alpha\left(x_{n}, f\left(x_{n}\right)\right) \geq 1
$$

Now, we have

$$
\begin{aligned}
\xi^{d\left(x_{n}, x^{*}\right)} & =\xi^{d\left(x_{n} f\left(x^{*}\right)\right)} \\
& \leq \xi^{s\left[d\left(x_{n} f\left(x_{n}\right)\right)+d\left(f\left(x_{n}\right), f\left(x^{*}\right)\right)\right]} \\
& =\xi^{s d\left(f\left(x_{n}\right), f\left(x^{*}\right)\right)} \xi^{s d\left(x_{n} f\left(x_{n}\right)\right)} \\
& =\left(\xi^{d\left(f\left(x_{n}\right), f\left(x^{*}\right)\right)}\right)^{s}\left(\xi^{d\left(x_{n} f\left(x_{n}\right)\right)}\right)^{s} \\
& \leq\left(\left(\alpha\left(x_{n}, f\left(x_{n}\right)\right) \alpha\left(x^{*}, f\left(x^{*}\right)\right)-1+\xi\right)^{d\left(f\left(x_{n}\right), f\left(x^{*}\right)\right)}\right)^{s}\left(\xi^{d\left(x_{n} f\left(x_{n}\right)\right)}\right)^{s} \\
& \leq\left(\xi^{\psi\left(d\left(x_{n}, x^{*}\right)\right)}\right)^{s}\left(\xi^{d\left(x_{n} f\left(x_{n}\right)\right)}\right)^{s} \\
& =\xi^{s \psi\left(d\left(x_{n}, x^{*}\right)\right)} \xi^{s d\left(x_{n} f\left(x_{n}\right)\right)} \\
& =\xi^{s\left[\psi\left(d\left(x_{n}, x^{*}\right)\right)+d\left(x_{n} f\left(x_{n}\right)\right)\right]} .
\end{aligned}
$$

Since $\xi>1$, we have

$$
d\left(x_{n}, x^{*}\right) \leq s\left[\psi\left(d\left(x_{n}, x^{*}\right)\right)+d\left(x_{n}, f\left(x_{n}\right)\right)\right]
$$

and $\psi$ is continuous at 0 and $d\left(x_{n}, f\left(x_{n}\right)\right) \rightarrow 0$ as $n \rightarrow \infty$. It implies that $x_{n} \rightarrow x^{*}$ as $n \rightarrow \infty$. Therefore, the fixed point equation (1.1) is well posed with respect to $\alpha$.

\section{Competing interests}

The authors declare that they have no competing interests.

\section{Authors' contributions}

All authors have carefully prepared, wrote and checked this manuscript including its final appearance.

\section{Author details}

'Department of Mathematics, Faculty of Science, King Mongkut's University of Technology Thonburi (KMUTT), 126 Pracha Uthit Rd., Bang Mod, Thung Khru, Bangkok, 10140, Thailand. ${ }^{2}$ Centre of Excellence in Mathematics, CHE, Si Ayutthaya Road, Bangkok, 10400, Thailand. ${ }^{3}$ Department of Mathematics and Statistics, Faculty of Science and Technology, Thammasat University Rangsit Center, Pathumthani, 12121, Thailand.

\section{Acknowledgements}

This research is supported by the Centre of Excellence in Mathematics, the Commission on High Education, Thailand, and also Miss Supak Phiangsungnoen is supported by the Centre of Excellence in Mathematics, the Commission on High Education, Thailand for Ph.D. at KMUTT. The second author would like to thank the Thailand Research Fund and Thammasat University under Grant No. TRG5780013 for financial support during the preparation of this manuscript. Moreover, the authors are grateful for the reviewers for careful reading of the paper and for suggestions which improved the quality of this work.

Received: 31 May 2014 Accepted: 7 August 2014 Published: 02 Sep 2014

\section{References}

1. Chandok, S, Postolache, M: Fixed point theorem for weakly Chatterjea-type cyclic contractions. Fixed Point Theory Appl. 2013, Article ID 28 (2013)

2. Shatanawi, W, Postolache, M: Common fixed point results of mappings for nonlinear contractions of cyclic form in ordered metric spaces. Fixed Point Theory Appl. 2013, Article ID 60 (2013) 
3. Shatanawi, W, Postolache, M: Common fixed point theorems for dominating and weak annihilator mappings in ordered metric spaces. Fixed Point Theory Appl. 2013, Article ID 271 (2013)

4. Miandaragh, MA, Postolache, M, Rezapour, Sh: Some approximate fixed point results for generalized $\alpha$-contractive mappings. Sci. Bull. 'Politeh.' Univ. Buchar., Ser. A, Appl. Math. Phys. 75(2), 3-10 (2013)

5. Miandaragh, MA, Postolache, M, Rezapour, S: Approximate fixed points of generalized convex contractions. Fixed Point Theory Appl. 2013, Article ID 255 (2013)

6. Shatanawi, W, Postolache, $\mathrm{M}$ : Coincidence and fixed point results for generalized weak contractions in the sense of Berinde on partial metric spaces. Fixed Point Theory Appl. 2013, Article ID 54 (2013)

7. Czerwik, S: Contraction mappings in b-metric spaces. Acta Math. Inform. Univ. Ostrav. 1, 5-11 (1993)

8. Bakhtin, IA: The contraction mapping principle in quasimetric spaces. Funct. Anal., Ulyanovsk Gos. Ped. Inst. 30, 26-37 (1989)

9. Sintunavarat, W, Plubtieng, S, Katchang, P: Fixed point result and applications on b-metric space endowed with an arbitrary binary relation. Fixed Point Theory Appl. 2013, Article ID 296 (2013)

10. Cosentino, M, Salimi, P, Vetro, P: Fixed point results on metric-type spaces. Acta Math. Sci. 34(4), 1237-1253 (2014)

11. Shatanawi, W, Pitea, A, Lazovic, R: Contraction conditions using comparison functions on b-metric spaces. Fixed Point Theory Appl. 2014, Article ID 135 (2014)

12. Czerwik, S: Nonlinear set-valued contraction mappings in b-metric spaces. Atti Semin. Mat. Fis. Univ. Modena 46, 263-276 (1998)

13. Berinde, V: Generalized contractions in quasimetric spaces. In: Seminar on Fixed Point Theory. Preprint, vol. 3, pp. 3-9 (1993)

14. Boriceanu, M, Bota, M, Petru, A: Multivalued fractals in b-metric spaces. Cent. Eur. J. Math. 8(2), 367-377 (2010)

15. Rus, IA: Generalized Contractions and Applications. Cluj University Press, Cluj-Napoca (2001)

16. Berinde, V: Contracţii generalizate şi aplicaţii. Editura Club Press 22, Baia Mare (1997)

17. Berinde, V: Sequences of operators and fixed points in quasimetric spaces. Stud. Univ. Babeş-Bolyai, Math. 16(4), 23-27 (1996)

18. Ulam, SM: Problems in Modern Mathematics. Wiley, New York (1964)

19. Hyers, DH: On the stability of the linear functional equation. Proc. Natl. Acad. Sci. USA 27(4), 222-224 (1941)

20. Bota-Boriceanu, MF, Petruşel, A: Ulam-Hyers stability for operatorial equations. An. Ştiinţ. Univ. 'Al... Cuza' laşi, Mat. 57, 65-74 (2011)

21. Cădariu, L, Găvruța, L, Găvruța, P: Fixed points and generalized Hyers-Ulam stability. Abstr. Appl. Anal. 2012, Article ID $712743(2012)$

22. Rus, IA: The theory of a metrical fixed point theorem: theoretical and applicative relevances. Fixed Point Theory 9(2), 541-559 (2008)

23. Rus, IA: Remarks on Ulam stability of the operatorial equations. Fixed Point Theory 10(2), 305-320 (2009)

24. Sintunavarat, $\mathrm{W}$ : Generalized Ulam-Hyers stability, well-posedness and limit shadowing of fixed point problems for $\alpha$ - $\beta$-contraction mapping in metric spaces. Sci. World J. 2014, Article ID 569174 (2014)

25. Haghi, RH, Postolache, M, Rezapour, Sh: On T-stability of the Picard iteration for generalized $\psi$-contraction mappings. Abstr. Appl. Anal. 2012, Article ID 658971 (2012)

26. Kutbi, MA, Sintunavarat, W: Ulam-Hyers stability and well-posedness of fixed point problems for $\alpha$ - $\lambda$-contraction mapping in metric spaces. Abstr. Appl. Anal. 2014, Article ID 268230 (2014)

27. Samet, B, Vetro, C, Vetro, P: Fixed point theorems for $\alpha$ - $\psi$-contractive type mappings. Nonlinear Anal. 75, 2154-2165 (2012)

28. Agarwal, RP, Sintunavarat, W, Kumam, P: PPF dependent fixed point theorems for an $\alpha_{c}$-admissible non-self mapping in the Razumikhin class. Fixed Point Theory Appl. 2013, Article ID 280 (2013)

29. Karapinar, E, Samet, B: Generalized $\alpha-\psi$-contractive type mappings and related fixed point theorems with applications. Abstr. Appl. Anal. 2012, Article ID 793486 (2012)

30. Karapinar, E, Sintunavarat, $W$ : The existence of an optimal approximate solution theorems for generalized $\alpha$-proximal contraction non-self mappings and applications. Fixed Point Theory Appl. 2013, Article ID 323 (2013)

31. Kutbi, MA, Sintunavarat, $\mathrm{W}$ : The existence of fixed point theorems via $w$-distance and $\alpha$-admissible mappings and applications. Abstr. Appl. Anal. 2013, Article ID 165434 (2013)

32. Usman Ali, M, Kamran, T, Sintunavarat, W, Katchang, P: Mizoguchi-Takahashi's fixed point theorem with $\alpha, \eta$ functions. Abstr. Appl. Anal. 2013, Article ID 418798 (2013)

33. Salimi, $\mathrm{P}$, Vetro, $\mathrm{C}$, Vetro, $\mathrm{P}$ : Fixed point theorems for twisted $(\alpha, \beta)-\psi$-contractive type mappings and applications. Filomat 27(4), 605-615 (2013)

34. Bota, M, Karapınar, E, Mleşniţe, O: Ulam-Hyers stability results for fixed point problems via $\alpha$ - $\psi$-contractive mapping in (b)-metric space. Abstr. Appl. Anal. 2013, Article ID 825293 (2013)

35. Berinde, V: Iterative Approximation of Fixed Points. Editura Efemeride, Baia Mare (2002)

10.1186/1687-1812-2014-188

Cite this article as: Phiangsungnoen et al.: Fixed point results, generalized Ulam-Hyers stability and well-posedness via $\alpha$-admissible mappings in b-metric spaces. Fixed Point Theory and Applications 2014, 2014:188 